\title{
A correlação entre a leptospirose e as condições socioambientais: ênfase na região do Cariri - CE, Brasil
}

Correlation between leptospirosis and socio-environmental conditions: emphasis in the Cariri - CE region, Brazil La correlación entre la leptospirosis y las condiciones sociales y ambientales: destaque en la región de Cariri - CE, Brasil

Agnes Jennine Alves BEZERRA

Discente, Curso de Graduação, Faculdade de Medicina Estácio de Juazeiro do Norte, 63040 Juazeiro do Norte - CE, Brasil https://orcid.org/0000-0002-6167-9104

Lucas Batista VIANA

Discente, Curso de Graduação, Faculdade de Medicina Estácio de Juazeiro do Norte, 63040 Juazeiro do Norte - CE, Brasil Marina Tavares FEITOSA

Discente, Curso de Graduação, Faculdade de Medicina Estácio de Juazeiro do Norte, 63040 Juazeiro do Norte - CE, Brasil Rayka Dantas Rodrigues ALVES Discente, Curso de Graduação, Faculdade de Medicina Estácio de Juazeiro do Norte, 63040 Juazeiro do Norte - CE, Brasil Daniel Gonçalves LEITE Discente, Curso de Graduação, Faculdade de Medicina Estácio de Juazeiro do Norte, 63040 Juazeiro do Norte - CE, Brasil

Djailson Ricardo MALHEIRO Docente, Curso de Graduação, Faculdade de Medicina Estácio de Juazeiro do Norte, 63040 Juazeiro do Norte - CE, Brasil https://orcid.org/0000-0002-2646-2698

\section{Resumo}

O presente artigo tem como objetivo estudar a Leptospirose, além de entender como está concentrada sua disseminação pelas regiões brasileiras, em especial a região do Cariri cearense, a fim de associar o ciclo de vida da bactéria e sua relação de contágio com a condição socioambiental da população em geral. Foi analisada a relação do número de residências com esgoto a céu aberto e sua interferência com a leptospirose, como a água das enchentes que fica acumulada devido à falta de uma drenagem adequada contribui para o aumento da doença. Nesse estudo também foi possível observar a escassez de estudos e artigos científicos que procurarem pesquisar e se aprofundar sobre o assunto na área da região do Cariri. Desse modo, foi possível observar a falta de atenção básica e políticas públicas por parte do governo, seja ele municipal ou estadual, em buscar promover uma condição de vida favorável para sua população, seja ela urbana ou rural. Em especial foi observado a falta de atenção a pessoas de uma certa faixa etária, tendo a maior média de contágio. Dessa forma, viu-se a necessidade de questionar e buscar se aprofundar cada vez mais sobre a questão, procurando sempre informar a população, a fim de que possa se evitar que o número de pessoas infectadas amplie.

Descritores: Leptospirose; Ciência, Tecnologia e Sociedade; Ambiente Sociocultural.

\section{Abstract}

This article aims to study Leptospirosis, in addition to understanding how its dissemination is concentrated in Brazilian regions, especially the Cariri region of Ceará, in order to associate the bacterium's life cycle and its contagious relationship with the socio-environmental condition of general population. The relationship between the number of residences with open sewage and its interference with leptospirosis was analyzed, as the flood water that accumulates due to the lack of adequate drainage contributes to the increase in the disease. In this study it was also possible to observe the scarcity of studies and scientific articles that seek to research and deepen on the subject in the area of the Cariri region. In this way, it was possible to observe the lack of basic attention and public policies on the part of the government, be it municipal or state, in seeking to promote a favorable living condition for its population, be it urban or rural. In particular, the lack of attention to people of a certain age group was observed, with the highest average of contagion. Thus, there was a need to question and seek to go deeper and deeper into the issue, always trying to inform the population, so that the number of infected people can be increased.

Descriptors: Leptospirosis; Science, Technology and Society; Cultural Characteristics.

\section{Resumen}

Este artículo tiene como objetivo estudiar la leptospirosis, además de comprender cómo se concentra su propagación por las regiones brasileñas, en particular la región Cariri de Ceará, con el fin de asociar el ciclo de vida de la bacteria y su relación de contagio con la condición socioambiental de la población general. población. Se analizó la relación entre el número de viviendas con alcantarillado abierto y su interferencia con la leptospirosis, ya que el agua de inundación acumulada por falta de drenaje adecuado contribuye al incremento de la enfermedad. En este estudio, también fue posible observar la escasez de estudios y artículos científicos que busquen investigar y profundizar en el tema en el área de la región de Cariri. Así, se pudo observar la falta de atención primaria y políticas públicas por parte del gobierno, ya sea municipal o estatal, en busca de promover unas condiciones de vida favorables para su población, ya sea urbana o rural. En particular, se observó la falta de atención a personas de un determinado grupo de edad, con la mayor media de contagio. Así, surgió la necesidad de cuestionar y buscar profundizar en el tema, buscando siempre informar a la población, para evitar que aumente el número de personas infectadas.

Descriptores: Leptospirosis; Ciencia, Tecnología y Sociedad; Características Culturales.

INTRODUÇÃO

\section{A Leptospirose é uma doença infecciosa} aguda e que pode tornar-se grave caso não seja precocemente diagnosticada. Ela é causada por bactérias do gênero Leptospira, sendo a mais comum a Leptospira interrogans, que é da espécie espiroqueta, gram-negativa aeróbica obrigatória e com flagelos periplásmicos, é transmitida por diferentes espécies de animais, entre eles: roedores, suínos, caninos e bovinos, que podem levar a contaminação dos seres humanos. O micro-organismo pode viver durante toda sua vida nos rins dos animais infectados, que quando urinam liberam essa carga bacteriana para o meio, que pode sobreviver por até seis meses depois de excretado, desde que esteja em solo úmido ou em água, com pH neutro ou alcalino, não sobrevivendo em águas com alto teor salino ${ }^{1}$.

O principal animal transmissor da leptospirose é o Rattus novergicus, o popular rato de esgoto, pelo fato de existir em grande quantidade nas cidades e da sua proximidade com os seres humanos. Assim, quando há 
enchentes ou água parada a urina do rato, se estiver contaminada com a $L$. interrogans, pode transmitir a doença a seres humanos. A infecção humana ocorre através da pele, mucosas ou a ingestão de água e alimentos contaminados. Um fator agravante para 0 contágio de leptospirose é a presença de cortes ou feridas na pele, o que facilita a contaminação. Contudo, os seres humanos são infectados de forma casual e transitoriamente, não tendo importância no ciclo da doença ${ }^{1,2}$.

A partir dessas informações, foi feita a busca de uma forma mais ampla, e foi possível observar que na região nordeste como um todo, e percebeu-se que no ano de 2010 tiveram apenas 37 casos confirmados, segundo a Rede Interagencial de Informações para a Saúde, mas esse estudo não se mostra atual, por possui dados com mais de 5 anos, tornando-se insuficiente e expondo a necessidade de novas pesquisas, com informações mais atualizadas e com métodos mais robustos ${ }^{3}$.

De acordo com Guimarães et al. ${ }^{4}$, uma das principais causas do aumento da leptospirose são as enchentes, que são um problema corriqueiro no Brasil. Segundo estimativas, ao menos 8 milhões de pessoas convivem diariamente com a ameaça de enchentes ou deslizamentos em suas residências. Essas enchentes ocorrem por diversos fatores, como: grande volume de chuvas devido ao desequilíbrio hídrico, construções feitas a margem de rios, problemas de escoamento, saneamento e descarte inadequado de lixo ${ }^{5}$.

Ao analisarmos a região do Cariri cearense, Brasil, vemos que a situação não é diferente, temos na região uma falta de infraestrutura para escoar a água das chuvas, levando ao acúmulo de água em algumas áreas, que pode levar dias para ser esgotada. E somado a isso, temos a presença e lixões e o descarte incorreto de resíduos em toda a cidade, fator esse que contribui de forma agravante no aparecimento de ratos $e$ ratazanas, tornando a região do Cariri cearense um lugar com grande potencial para 0 desenvolvimento e proliferação de uma doença como a leptospirose, que se não tiver uma atenção básica pode chegar a ser uma doença endêmica na região durante a quadra chuvosa ${ }^{6}$.

Com isso, é possível estabelecer uma comparação entre o risco de contaminação a leptospirose e condição socioambiental em que o indivíduo está inserido. Visto sua forma de contágio e as práticas que geralmente são exercidas por pessoas do campo e/ou que não tem uma condição social elevada, como aponta
Buffon $^{7}$ ao afirmar que a leptospirose humana, doença infeciosa aguda. apresenta como condicionantes socioambientais o esgotamento sanitário, o lixo, a fonte de água, a condição de moradia, a ocorrência de episódios de inundações e alagamentos, a alfabetização, a renda, dentre outros fatores.

De Oliveira et al. $^{8}$ destacam em seus estudos que há ausência de interesse por parte do poder público em analisar como a leptospirose está diretamente ligadas a região do Cariri cearense, e mostrar como a região, em especial sua população mais carente, está à mercê de doenças infecciosas que estão relacionadas a sua condição de moradia e a suas ações diárias, devido a falta de investimento e melhorias sanitárias na região.

MATERIAL E MÉTODO

A pesquisa segue a proposta de revisão de literatura, visto o interesse em compreender e estudar o problema da leptospirose, com ênfase na região do Cariri cearense. Trata-se de pesquisa de natureza básica com métodos qualiquantitativos com abordagem descritiva, sendo utilizados ainda métodos dedutivo e comparativo. Os artigos foram obtidos nas bases Scielo, Google Acadêmico, Periódicos. Usando palavras-chave como Leptospirose e Cariri. Cabe citar que para o estudo foi realizado a filtragem de informações com os seguintes critérios de inclusão: informações centradas na saúde primária (visto que ela é muito importante para a prevenção da leptospirose), artigos que abordassem a temática na Região do Cariri cearense e que possuíssem a língua oficial da região abordada: Português; e os seguintes critérios de exclusão: artigos que abordassem a temática em outros países ou regiões, que não estivessem em Português, que não respondiam a questão da pesquisa e estudos não concluídos. A partir disso, foram selecionados 25 estudos, mas 7 foram excluídos devido à sua incompatibilidade com os critérios, restando 19, contendo 5 sites, como o do "Trata Brasil", "Diário do Nordeste".

A princípio, foi escolhido o tema, a fim de contemplar a importância social, e sua correlação com a saúde, levando em consideração a necessidade de explorar essa questão, visto a escassez de estudos sobre, principalmente na região do Cariri cearense. Tendo em vista que essa falta coopera de forma significativa com a estagnação da situação socioambiental precária de muitas cidades na região, dificultando o acesso a informações e consequentemente, dificultando uma iniciativa do poder público. A região estudada apresenta carência na drenagem hídrica com tendência a 
ter número elevado de enchentes, aumentando a disseminação da doença; tendo ainda outro agravo: a quantidade de terrenos baldios e lixo a céu aberto, tornando vulnerável a situação das pessoas menos favorecidas economicamente, visto que essas pessoas costumam ter mais contato com regiões suscetíveis a leptospirose. Posteriormente, foi feita uma busca de forma mais ampla, na Região Nordeste como um todo, levando em consideração os dados fornecidos pelo Ministério da Saúde ${ }^{9}$, assim como os dados fornecidos pela revista "Diário do Nordeste"10. A quantidade de artigos encontrados não se apresenta na atualidade, por reunir publicações de mais de 5 anos, reforçando a necessidade de novas pesquisas sobre o tema.

RESULTADOS E DISCUSSÃO

Com base nos resultados obtidos foi possível observar que o número de casos da leptospirose está diretamente relacionado com a qualidade de vida da população, assim como com o local em que a população está inserida. Outra observação a ser analisada deve levar em conta os dados obtidos através do DATASUS e do SINAN, que nos permitiu perceber que a maior parte dos casos de leptospirose no Brasil se concentra na parcela da população que geralmente é economicamente ativa, 20 a 39 anos. Informação colhida a partir da análise de dados da leptospirose por faixa etária e de acordo com a unidade da Federação no ano de 2010, através do SINAN ${ }^{11}$ (Tabela 1 ).

Esse fator, idade maior de risco, pode estar relacionado com os nuances que essa população enfrente diariamente, em especial nas épocas chuvosas, para ir de encontro ao seu local de trabalho. É de suma importância levar em conta que essa parcela da população não tem a possibilidade de faltar seu dia de trabalho em dias chuvosos, e muitas vezes acabam se sujeitando a enfrentar condições adversas, como é o caso das enchentes, o que os faz ser muito mais suscetível a doenças como a leptospirose.

Além disso, é importante ressaltar que no Brasil, em especial regiões nordestinas, e na região do cariri cearense, há um número elevado de lixo, jogado a céu aberto, o que favorece de maneira exponencial o aumento da quantidade de ratos na região, favorecendo a transmissão da leptospirose, caso esses animais estejam infectados ${ }^{12}$.

Essa quantidade de lixo a céu aberto favorece o maior número de enchentes, visto o entupimento de bueiros. De acordo com a revista "Diário do Nordeste", a média de chuvas na região do cariri cearense na quadra chuvosa é de cerca de 66,1 milímetros, e que cidades como o Crato, que faz parte da região do cariri, já vem apresentando a anos problemas relacionados a enchentes em seu canal do rio granjeiro, provocando durante dias o acúmulo de água na área, que em períodos de seca serve como depósito de lixo por parte da população, o que nos retrata ao aumento de ratos, que podem contaminar essa água com a bactéria da leptospirose ${ }^{10}$.

Outra questão que foi possível observar na região do Cariri cearense é a falta de saneamento, que tem contribuído de forma relevante no risco de casos na região, assim como a falta de uma rede de esgoto, que apresenta números baixos ao analisarmos uma região como o Cariri. Dessa forma, principalmente nas periferias da cidade, cerca de $84,6 \%$ da população da região metropolitana do Cariri cearense, convivem diariamente tendo contato com esgotos a céu aberto. Sendo assim, é notório que os moradores dessas regiões se arriscam ao necessitar entrar em contato com líquido sem o tratamento adequado e que podem estar contaminados. Dados esses que podem ser comprovados a partir do artigo "A importância do saneamento básico para a saúde nos 9 municípios cearenses na região metropolitana do Cariri" realizado pela Trata Brasil, uma sociedade civil de interesse público, através desse artigo podemos constatar a porcentagem da população que convive com esgoto a céu aberto em cidades do Cariri ${ }^{13,14}$ (Gráfico 1).

Tabela 1. Distribuição dos casos de leptospirose no Brasil de acordo com idade e unidade da federação (Adaptado SINAN ${ }^{11}$ )

\begin{tabular}{|c|c|c|c|c|c|c|c|c|c|}
\hline \multirow[b]{2}{*}{$\begin{array}{l}\text { Unidade da } \\
\text { federação }\end{array}$} & \multicolumn{8}{|c|}{ Idade } & \multirow[b]{2}{*}{ Total } \\
\hline & $\begin{array}{l}<1 \\
\text { ano }\end{array}$ & $\begin{array}{l}1-4 \\
\text { anos }\end{array}$ & $\begin{array}{l}-9 \\
\text { anos }\end{array}$ & $\begin{array}{l}\text { 10-19 } \\
\text { anos }\end{array}$ & $\begin{array}{l}\text { 20-39 } \\
\text { anos }\end{array}$ & $\begin{array}{l}40-59 \\
\text { anos }\end{array}$ & 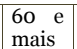 & $\begin{array}{l}\text { Idade } \\
\text { ignorada }\end{array}$ & \\
\hline São Paulo & 9 & 6 & 15 & 117 & 358 & 304 & 74 & - & 883 \\
\hline $\begin{array}{l}\text { Rio Grande do } \\
\text { Sul }\end{array}$ & 1 & - & 5 & 46 & 175 & 196 & 40 & - & 463 \\
\hline Santa Catarina & 5 & 2 & 4 & 51 & 182 & 174 & 22 & - & 440 \\
\hline Paraná & 3 & - & 5 & 53 & 124 & 112 & 34 & - & 331 \\
\hline Rio de Janeiro & 2 & - & 5 & 35 & 104 & 108 & 35 & - & 289 \\
\hline Espírito Santo & - & 1 & 13 & 50 & 118 & 74 & 20 & - & 276 \\
\hline Pernambuco & 1 & 3 & 19 & 50 & 118 & 66 & 17 & - & 274 \\
\hline Bahia & 6 & - & 2 & 35 & 83 & 63 & 14 & - & 203 \\
\hline Minas Gerais & 1 & - & 1 & 11 & 31 & 38 & 14 & - & 96 \\
\hline Pará & - & 2 & 2 & 12 & 43 & 31 & 6 & - & 96 \\
\hline Alagoas & - & - & 2 & 17 & 36 & 15 & 2 & - & 72 \\
\hline Sergipe & - & - & - & 12 & 25 & 28 & 4 & - & 69 \\
\hline Amapá & 1 & 3 & 9 & 21 & $\begin{array}{l}25 \\
15\end{array}$ & 10 & $\begin{array}{l}4 \\
3 \\
\end{array}$ & - & 62 \\
\hline Acre & - & - & 1 & 8 & 19 & 14 & 2 & - & 44 \\
\hline Amazonas & - & - & 1 & 9 & 18 & 11 & 2 & - & 41 \\
\hline Maranhão & - & 2 & 3 & 7 & 14 & 7 & 4 & 1 & 38 \\
\hline Ceará & - & 1 & 1 & 4 & 15 & 10 & 6 & - & 37 \\
\hline Distrito Federal & - & - & - & 2 & 10 & 16 & 1 & - & 29 \\
\hline $\begin{array}{l}\text { Rio Grande do } \\
\text { Norte }\end{array}$ & - & 1 & 2 & - & 5 & 10 & 3 & - & 21 \\
\hline Rondônia & - & - & - & 7 & 3 & 5 & - & - & 15 \\
\hline Goiás & - & - & - & 2 & 7 & 5 & - & - & 14 \\
\hline Paraíba & - & - & - & 2 & 2 & $\frac{3}{2}$ & 2 & - & 8 \\
\hline Mato Grosso & - & - & - & 1 & 1 & 2 & - & - & 4 \\
\hline $\begin{array}{l}\text { Mato Grosso do } \\
\text { Sul }\end{array}$ & - & - & - & - & 2 & - & - & - & 2 \\
\hline Roraima & - & - & - & 1 & - & - & 1 & - & 2 \\
\hline Tocantins & - & - & - & - & 2 & - & - & - & 2 \\
\hline Piauí & - & - & - & - & - & - & - & - & - \\
\hline UF ignorada & - & - & - & - & - & - & - & - & - \\
\hline TOTAL & 29 & 21 & 90 & 553 & 1.510 & 1.301 & 306 & 1 & 3.811 \\
\hline
\end{tabular}




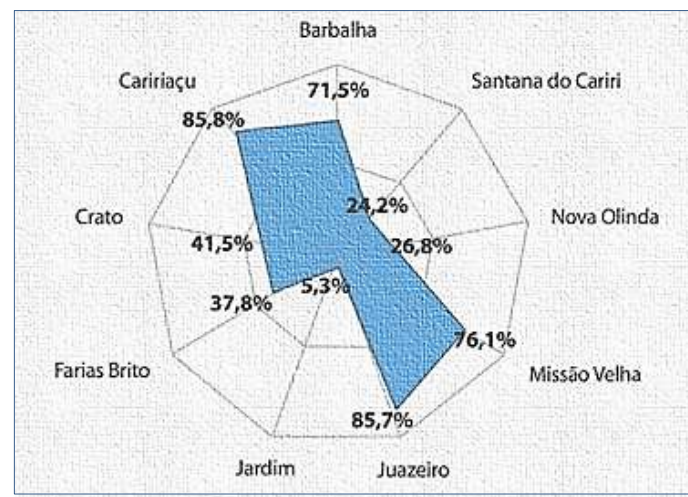

Gráfico 1: Distribuição dos casos de leptospirose na região do Cariri cearense (Adaptado IBGE ${ }^{12}$, Fonte TRATA BRASIL ${ }^{13}$ ).

Assim, a partir desse estudo do Trata Brasil, foi possível associarmos essas condições sanitárias aos aspectos econômicos da população, mostrando a realidade em que vive grande parcela da população caririense, que diversas vezes está desassistidas pelos seus governantes ${ }^{14-19}$.

No site do Ministério da Saúde ${ }^{9}$ colhemos informações acerca do diagnóstico e tratamento da leptospirose através do Sistema Público de Saúde, o que revelou os seguintes fatores, deve ser realizado anamnese e exame físico, além de exames, hemograma e bioquímica (uréia, creatinina, bilirrubina total e frações, TGO, TGP, gama-GT, fosfatase alcalina e CPK, $\mathrm{Na}+$ e $\mathrm{K}+$ ). Se necessário, também devem ser solicitados: radiografia de tórax, eletrocardiograma (ECG) e gasometria arterial, além de exames sorológicos para diagnóstico, teste ELISA-IgM e a microaglutinação (MAT) (Tabela 2) ${ }^{9}$.

Tabela 2. Tipos de diagnóstico da leptospirose (Adaptado Ministério da Saúde ${ }^{9}$ )

\begin{tabular}{l|l}
\hline \multicolumn{2}{c}{ Tipo de diagnóstico - Microaglutinação } \\
\hline Tipo de material & Soro (sem hemólise) \\
\hline Quantidade & $3,0 \mathrm{Ml}$ \\
\hline Número de amostras & 2 \\
\hline Período de coleta & $\begin{array}{l}\text { Amostras pareadas nas fases agudas e convalescente: a } \\
\text { primeira no primeiro atendimento e a segunda após um } \\
\text { intervalo de 14 a 21 (máx 6o) dias }\end{array}$ \\
\hline Recipiente & $\begin{array}{l}\text { Frasco adequado para congelamento (tubo de ensaio) } \\
\text { sem anticoagulante }\end{array}$ \\
\hline Transporte & No gelo $\left(4^{\circ} \mathrm{C}\right)$ \\
\hline Estocagem longo prazo & Congelado $-20^{\circ} \mathrm{C}$ \\
\hline \multicolumn{2}{c}{ Tipo de diagnóstico - ELISA-IgM } \\
\hline Tipo de material & Soro (sem hemólise) \\
\hline Quantidade & 3,0 ml \\
\hline Número de amostras & 10u 2 \\
\hline Período de coleta & $\begin{array}{l}\text { Fase aguda (no primeiro atendimento); se for negativo, } \\
\text { coleta uma segunda amostra em 5-7 dias. }\end{array}$ \\
\hline Recipiente & $\begin{array}{l}\text { Frasco adequado para congelamento (tubo de ensaio) } \\
\text { sem anticoagulante }\end{array}$ \\
\hline Transporte & No gelo $\left(4^{\circ} \mathrm{C}\right)$ \\
\hline Estocagem longo prazo & Congelado $-20^{\circ} \mathrm{C}$ \\
\hline Fonte: Dados da pesquisa
\end{tabular}

Outro ponto a ser analisado é a falta de estudos acerca da leptospirose focado na região do Cariri cearense, sendo possível encontrar e analisar apenas dados desatualizados, que não refletem de forma confiável a real situação da leptospirose na região. É possível visualizar que a área tem grande potencial para números elevados da leptospirose, devido a todos os fatores que promovem a sua proliferação, contudo não é possível comprová-los devido a falta de estudo centrada na região. Esse tipo de estudo é suma importância para o setor público buscar atuar de forma mais eficiente em determinadas áreas do território, visto a incidência da doença tanto em regiões urbanas quanto rurais, mesmo com a predominância de casos em centros urbanos.

CONCLUSÃO

Como podemos observar, a escassez de estudos sobre a leptospirose na região do Cariri cearense é um ponto crucial a ser observado. É notória a necessidade da realização de pesquisas a fim de que possamos estudar e determinar como essa doença atinge a microrregião em estudo. Visto isso, é necessário enfatizar que a região se encontra desassistida no quesito doença e na vulnerabilidade da sua população.

Esses estudos e mapeamentos são de suma importância pelo fato de que a leptospirose é uma doença de fácil diagnostico, mas que se não tiver uma atenção, e houver a progressão do quadro, seus sintomas podem se agravar e o paciente pode chegar a ir a óbito. Devido a isso, vemos a importância de se mapear a região e descobrir as regiões mais vulneráveis a doença, a fim de promover uma maior atenção a essas áreas por parte do poder público, buscando conscientizar sua população.

Assim como, faz-se necessário uma maior atuação do poder público com o objetivo de promover melhorias na infraestrutura das cidades, com obras de saneamento básico, que segundo dados informados, são extremamente escassos em alguns municípios da região do cariri, obras de drenagem em diversos pontos dos municípios, a fim de possibilitar o escoamento das águas das chuvas para que não se acumulem e assim diminuir o risco de contaminação por parte da população que entra em contato com essa água.

$\mathrm{Na}$ mesma toada, foi observada a importância do poder público em uma maior atenção a população economicamente ativa do município, visto que apresentou ser uma população mais suscetível a se contaminar com a doença, que pode estar relacionada a diversos fatores, como falta de transporte público, onde a população precisa se sujeitar a ir a pé, enfrentando o acúmulo de água em períodos de chuva, ou mesmo a falta de equipamentos de proteção individual para os funcionários do municípios, que muitas vezes se sujeitam a trabalhos que promovem esse risco, como garis e funcionários do setor de abastecimento de água. 


\section{REFERÊNCIAS}

1. Martins FSV, Castiñeiras TMPP - Cives Centro de informação em saúde para viajantes - UFRJ - Informação - Leptospirose. Disponível em: http://www.cives.ufrj.br/informacao/leptospirose/ lep-iv.html. Acesso em 18/10/2020.

2. Pelissari DM, Maia-Elkhoury ANS, Arsky MLNS, Nunes ML. Revisão sistemática dos fatores associados à leptospirose no Brasil, 2000-2009. Epidemiol Serv Saúde. 2011;20(4):565-74.

3. Brasil. DATASUS - Leptospirose - Casos confirmados notificados no sistema de informação de agravos de notificação. Disponível em: http://tabnet.datasus.gov.br/cgi/tabcgi.exe?sina nnet/cnv/leptobr.def. Acesso em 10/11/2020.

4. Guimaraes RM, Cruz OG, Pereira VG, Mazoto ML, Vieira JD, Asmus CIRF. Análise temporal da relação entre leptospirose e ocorrência de inundações por chuvas no município do Rio de Janeiro, Brasil, 2007-2012. Ciênc. saúde coletiva. 2014;19(9):3683-92.

5. Freitas CM; Ximenes EF. Enchentes e saúde pública: uma questão na literatura científica recente das causas, consequências e respostas para prevenção e mitigação. Ciênc. saúde coletiva. 2012;17(6):1601-16.

6. Correia VMS, De Aquino MD. Thomaz ACF. Correia MLV Estudo de caso: aspectos e impactos perceptíveis na localização de lixões municipais utilizando a ferramenta $\mathrm{M}$ MACBETH. Rev DAE. 2018;66(211):35-49.

7. Buffon EPM. A leptospirose humana no AURMC (aglomerado urbano da região metropolitana de Curitiba/Pr) - risco vulnerabilidade socioambiental [dissertação]. Curitiba: Programa de Pós-Graduação em Geografia, Universidade Federal do Paraná (UFPR); 2016.

8. De Oliveira DSC. Guimarães, MJB. Medeiros Z - UFG - Modelo produtivo para leptospirose. Rev Patol Trop. 2009;38(1):17-26.

9. Ministério da Saúde - Leptospirose: Diagnóstico e Manejo clínico. 2009. Disponível em:

http://bvsms.saude.gov.br/bvs/publicacoes/lept ospirose-diagnostico-manejo-clinico2.pdf > Acesso em 30/10/2020.

10. Rodrigues A, Barbosa $H$. Comunidades que sofreram com enchentes continuam em risco.. Disponível em: https://diariodonordeste.verdesmares.com.br/re giao/comunidades-que-sofreram-comenchentes-continuam-em-risco-1.3006624. Acesso em: 02/11/2020.

11. SINAM. Sistema de informações de Agravos de notificação - Ceará - Nordeste - 2010. Disponível https://portalsinan.saude.gov.br/. Acesso em: 20/10/2020.

12. Philippe P. Cariri sustentável - O lixo bom. Disponível em: https://caririrevista.com.br/olixo-bom/. Acesso em 18/11/2020

13.IBGE. Instituto Brasileiro de Geografia e Estatística. Disponível em https://cidades.ibge.gov.br/brasil/ce/fortaleza/pe squisa/10087/76819. Acesso 10/11/2020.

14. TRATA BRASIL, A importância do saneamento básico para a saúde nos 9 municípios cearenses na região metropolitana do Cariri. Disponível em: < http://www.tratabrasil.org.br/datafiles/estudos/c ariri/folder-cariri.pdf > Acesso em: 21/10/2020.

15. TRATA BRASIL. Leptospirose está diretamente ligada à falta de saneamento. Disponível em: http://www.tratabrasil.org.br/blog/2017/08/01/fal ta-de-saneamento-agrava-leptospirose/. Acesso em: 15/11/2020.

16. Enchentes - Principais causas de inundações e histórico no Brasil. Disponível em: https://noticias.r7.com/hora-7/segredos-domundo/enchentes-principais-causas-deinundacoes-e-historico-no-brasil26092020\#: :text=Enchentes\%20\%2D\%20prin cipais $\% 20$ causas $\% 20$ de $\% 20$ inunda\%C3\%A7\% C3\%B5es\%20e\%20hist\%C3\%B3rico\%20no\%2 OBrasil,-

Segredos\%20do\%20Mundo\&text=0\%20ac\%C 3\%BAmulo\%20de\%20lixo\%20nos,e\%20bueiro s\%2C\%20que\%20ficam\%20bloqueados.> Acesso em: 19/10/2020.

17. Spink MJP, Martins MHM. A leptospirose humana como doença duplamente negligenciada no Brasil. Ciênc saúde coletiva. 2020;25(3):919-28.

18. Varella D. Doenças e sintomas: Leptospirose. Disponível em: https://drauziovarella.uol.com.br/doencas-esintomas/leptospirose/\#: :text=Leptospirose $\% 2$ 0\%C3\%A9\%20uma\%20infec\%C3\%A7\%C3\%A 3o\%20causada,vermelhas $\% 20$ no $\% 20$ corpo $\% 2$ 0e\%20meningite. Acesso em: 18/10/2020.

19. Huttner MD, Pereira HCP, Tanaka RM. Pneumonia por leptospirose. J. Pneumol. 2002; 28(4):229-32. 


\section{CONFLITO DE INTERESSES}

Os autores declaram não haver conflitos de interesse

\section{AUTOR PARA CORRESPONDÊNCIA}

\section{Lucas Batista Viana}

Faculdade de Medicina Estácio de Juazeiro do Norte, 63040 Juazeiro do Norte - CE, Brasil

E-mail: I.batistaviana@gmail.com

Submetido em 21/11/2020

Aceito em 18/07/2021 